\title{
Association of obstructive sleep apnea with hypertension: A systematic review and meta-analysis
}

\author{
Haifeng $\mathrm{Hou}^{1,2,{ }^{*}}$, Yange Zhao ${ }^{3,}$, \\ Wenqing $\mathrm{Yu}^{3, *}$, Hualei Dong ${ }^{4}$, \\ Xiaotong Xue ${ }^{4}$, Jian Ding ${ }^{4}$, Weijia \\ Xing ${ }^{1, *}$, Wei Wang ${ }^{1,2^{*}}$ \\ ${ }^{1}$ School of Public Health, Taishan Medical \\ University, Taian, China \\ ${ }^{2}$ School of Medical and Health Sciences, Edith \\ Cowan University, Perth, Australia \\ ${ }^{3}$ School of Basic Medical Science, Taishan \\ Medical University, Taian, China \\ ${ }^{4}$ Taishan Hospital of Shandong Province, Taian, \\ China \\ * These authors contributed equally to the article
}

Background Obstructive sleep apnea (OSA) is a sleep disorder characterized as complete or partial upper airflow cessation during sleep. Although it has been widely accepted that OSA is a risk factor for the development of hypertension, the studies focusing on this topic revealed inconsistent results. We aimed to clarify the association between OSA and hypertension, including essential and medication-resistant hypertension.

Methods The Preferred Reporting Items for Systematic Reviews and Meta-Analyses (PRISMA) was followed. PubMed and Embase databases were used for searching the relevant studies published up to December 31,2016 . A quantitative approach of meta-analysis was performed to estimate the pooled odds ratio (OR) and 95\% confidence interval (CI).

Results Twenty-six studies with 51623 participants (28314 men, 23309 women; mean age 51.8 years) met inclusion criteria and were included in this study. Among them, six studies showed a significant association between OSA and resistant hypertension (pooled $\mathrm{OR}=2.842,95 \% \mathrm{CI}=1.703-3.980, P<0.05)$. Meanwhile, the combination of 20 original studies on the association of OSA with essential hypertension also presented significant results with the pooled ORs of $1.184(95 \% \mathrm{CI}=1.093-1.274, P<0.05)$ for mild OSA, $1.316(95 \%$ $\mathrm{CI}=1.197-1.433, P<0.05)$ for moderate OSA and $1.561(95 \%$ $\mathrm{CI}=1.287-1.835, P<0.05)$ for severe OSA.

Conclusions Our findings indicated that OSA is related to an increased risk of resistant hypertension. Mild, moderate and severe OSA are associated essential hypertension, as well a dose-response manner relationship is manifested. The associations are relatively stronger among Caucasians and male OSA patients.

\section{Correspondence to:}

Wei Wang

School of Medical and Health Sciences

Edith Cowan University

Perth, WA 6027

Australia

wei.wang@ecu.edu.au

Weijia Xing

School of Public Health

Taishan Medical University

2 Yingsheng East Road,

Taian 271000

PR China

71206930@qq.com
Obstructive sleep apnea (OSA) is a sleep disorder characterized as complete or partial upper airflow cessation during sleep, which mainly results from narrowed oropharyngeal or velopharyngeal anatomy $[1,2]$. OSA is reported to affect approximately $17 \%$ of American adults [3]. Hereditable dimension of craniofacial skeleton, obesity, and aging are considered risk factors for OSA, and the lack of neurophysiological regulation on airway dilator muscles also contributes to the causality of OSA [4]. Apart from causing uncomfortable symptomatology, untreated OSA is widely acknowledged to be associated with diabetes, cardiovascular disease and cerebrovascular disease [5]. Observational studies have illustrated that the prevalence of OSA is over 30\% among hypertension patients and nearly $80 \%$ among resistant hypertensive patients $[6,7]$. Although the association between OSA and hypertension is considered obvious, the published results regarding this relation- 
ship are not consistent [3]. More than eight studies reported that OSA is not associated with hypertension, arousing skepticism of the effect of OSA on the risk for hypertension $[2,8]$. To our knowledge, the effect of continuous positive airway pressure (CPAP) therapy on blood pressure (BP) reduction improves the establishment of the causal association of OSA with hypertension and cardiovascular diseases [8]. However, a recent meta-analysis demonstrated that CPAP intervention does not reduce cardiovascular risk [9]. Besides another meta-analysis on CPAP treatment trials found a low reduction of HP (2.6 mm Hg for systolic BP and $2.0 \mathrm{~mm} \mathrm{Hg}$ for diastolic BP) among OSA participants [10]. It has been manifested that CPAP may not be a sole hypertension intervention option for OSA patients [11]. To determine if OSA plays an independent causal role in hypertension, we conducted this systematic review and meta-analysis, and synthesized the studies on the association of OSA with essential hypertension and medication-resistant hypertension.

\section{MATERIALS AND METHODS}

We followed the criteria of the Preferred Reporting Items for Systematic Reviews and Meta-Analyses (PRISMA). The reported PRISMA Checklist is provided in Table S1 in Online Supplementary Document. The protocol of this study has been registered in PROSPERO (No. CRD42017064336), available at https:// www.crd.york.ac.uk/PROSPERO/.

\section{Search strategy}

The databases of PubMed and Embase were searched for literature published up to December 31, 2016. The search strategy was designed as a combination of the following key words: "obstructive sleep apnea" or "obstructive sleep apnea syndrome" or "sleep apnea" or "sleep disordered breathing" or "OSA" or "OSAS" or "SDB" and "hypertension" or "HTN". In addition, studies cited in the references at the retrieved articles were further screened.

\section{Selection criteria and quality assessment}

Two authors independently reviewed the title, abstract and full text of the publications to determine the suitability for inclusion. Eligible studies were included based on the following criteria: 1) studies conducted on human populations; 2) studies conducted to investigate the relationships between OSA and essential and/or resistant hypertension; 3) case-control studies, case-control comparison of baseline data in cohort populations or clinical populations, and cohort studies; 4) odds ratios (OR) and 95\% confidence interval (CI) available or can be calculated; 5) OSA patients diagnosed with polysomnography, and classified with apnea-hypopnea index (AHI); 6) studies published in English. We evaluated the methodological quality of each study according to the quality assessment scale by reference to PRISMA statement and MOOSE guideline (Table S2 and Table S3 in Online Supplementary Document).

\section{Data extraction}

Original data were retrieved independently from the eligible publications by two authors. The following data were extracted: author's name, year of publication, ethnicity of participants, type of study design, sample size, characteristics of the participants. If results derived from the same population were published more than once, the most recent publication or the one with the largest population size was enrolled. If a publication investigated the baseline data, and also studied the association of recent-onset hypertension with OSA among different numbers of participants through a follow-up, the investigations were treated as two independent studies. Data in all subgroups were collected when the authors reported results with age or gender stratification. The adjusted ORs were extracted from articles.

\section{Statistical analysis}

All statistical analyses were performed with the Stata14.0 software (Stata Corp, College Station, TX, USA). The pooled ORs and 95\% CIs were calculated to assess the strength of the association between OSA and hypertension. Q test and $I^{2}$ statistic were used to evaluate heterogeneity across the involved studies. When $I^{2}<50 \%$ and $P>0.10$, the fixed effect model was used to combine data sets. Otherwise, the random effect model was applied. Moreover, we conducted subgroup meta-analysis based on ethnicity of the population when heterogeneity was ultra $\left(I^{2}>50 \%\right.$ or $\left.P<0.10\right)$. To assess the robustness of the combined results and evaluate the effect of individual studies on this meta-analysis, we carried out sensitivity analysis by 
removing each study one at a time. Subsequently, the publication bias was assessed by the Funnel Plot analysis, and Egger's regression asymmetry test was further complemented. The Trim and Fill method was used to adjust the significant publication bias.

\section{RESULTS}

\section{Eligible studies}

Our initial screen returned 15031 publications in English, of which 4314 were from Pubmed and 10717 were from Embase. YZ and WY independently excluded 13846 ineligible articles through reviewing the titles, leaving 1185 articles for further abstract review. Among them, 26 publications with 51623 participants (28314 men, 23309 women; mean age 51.8 years) met all the inclusion criteria and were enrolled in meta-analysis [1,2,8,12-34]. Among those 1159 publications excluded at the last round: 365 were du-

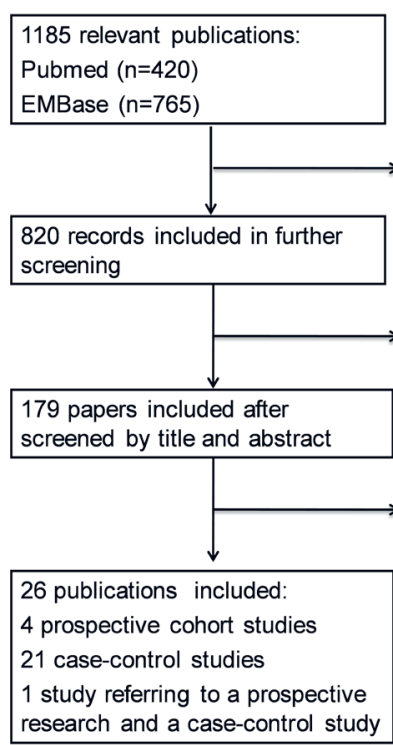

plicate articles, 311 studies did not refer to OSA or hypertension according to the current definitions, 167 were not original studies, 42 studies were not designed as required method, 73 studies did not have appropriate diagnostic criteria for OSA patients, 38 studies investigated other types of hypertension, and 163 were not human-based research. The flowchart for the process of screening articles is shown in Figure 1. Among all the enrolled publications, 21 articles reported case-control comparison in cross-sectional studies or baseline data of cohort studies [1,2,12-18,20,22-32], Four were prospective studies $[19,21,33,34]$, and one article reported both a baseline data comparison and a prospective study [8]. In terms of the study topics, six studies investigated the relationship between OSA and resistant hypertension [1,12-16], and 20 studies investigated the association of OSA with essential hypertension [2,8,17-34]. Individual characteristics of overall studies are summarized in Table 1 and Table S4 in Online Supplementary Document.

Figure 1. Flowchart of the study selection.

\section{Association between OSA and resistant hypertension}

We included six studies that explored the relationship between OSA and resistant hypertension [1,1216], with five studies conducted among Caucasians and one study was among Asians. The synthesized results showed that OSA was significantly associated with resistant hypertension with a pooled OR of 2.842 (95\% CI=1.703-3.980, P<0.05) (Figure 2 and Table 2), which indicated that OSA participants

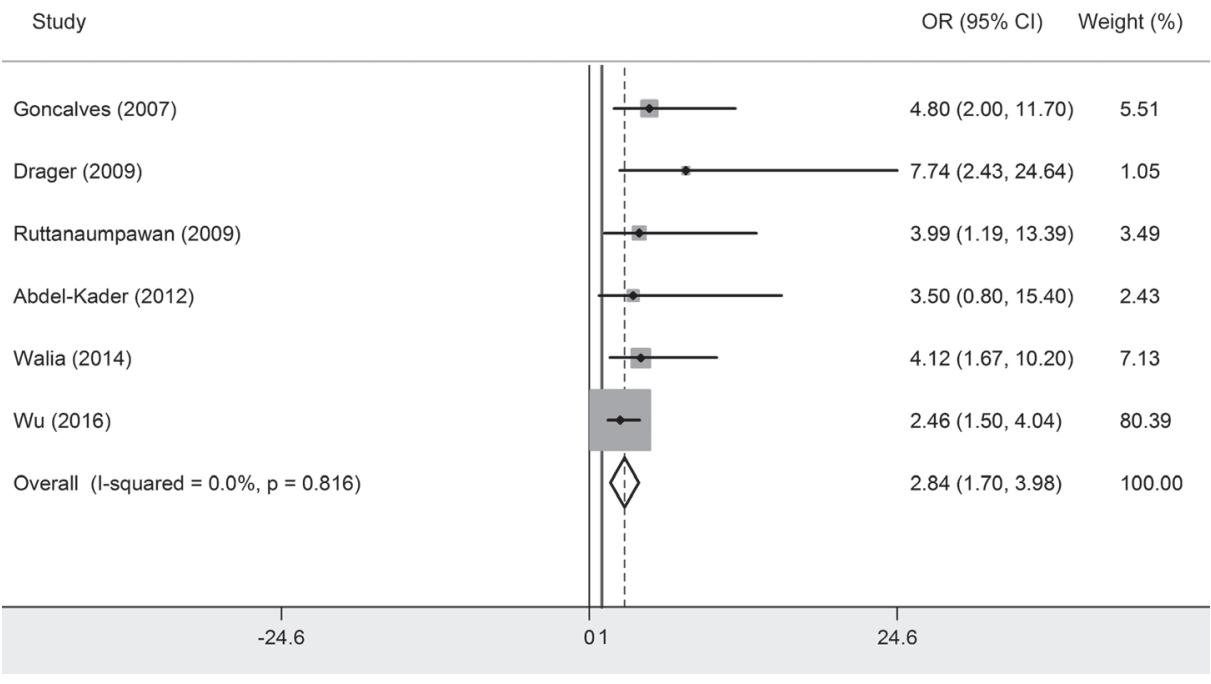

Figure 2. Forest plot of the association between resistant hypertension and obstructive sleep apnea (OSA). 


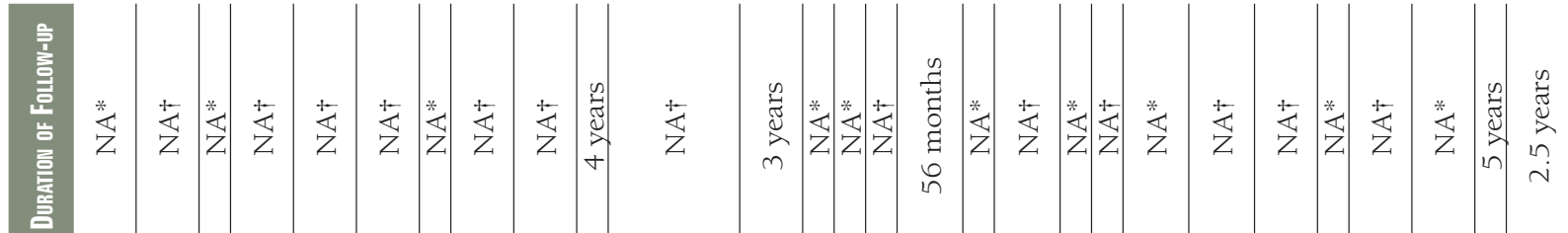

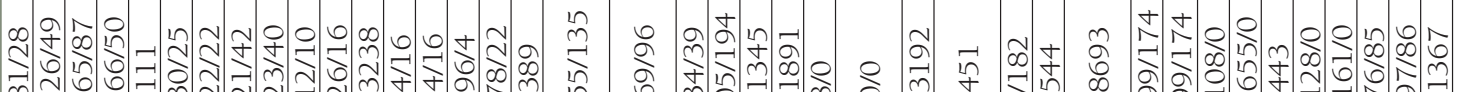

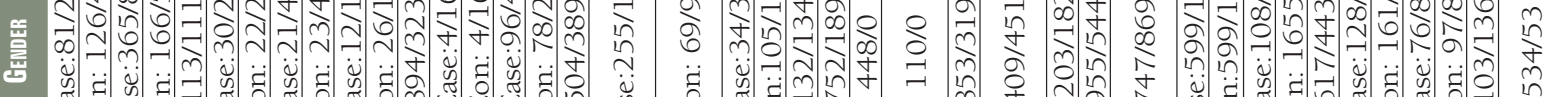
Und

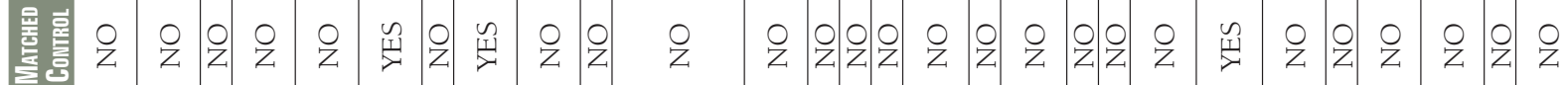
b.

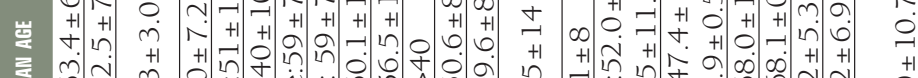

츨

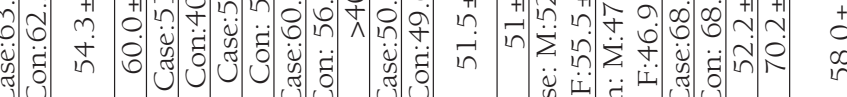

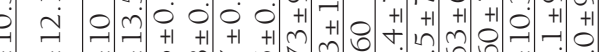

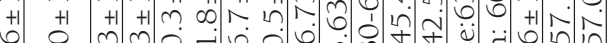
i. 凹ூ

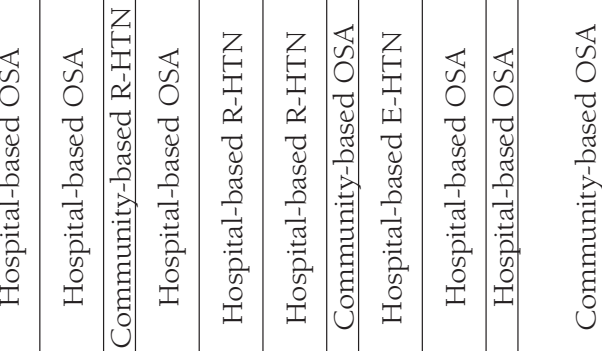

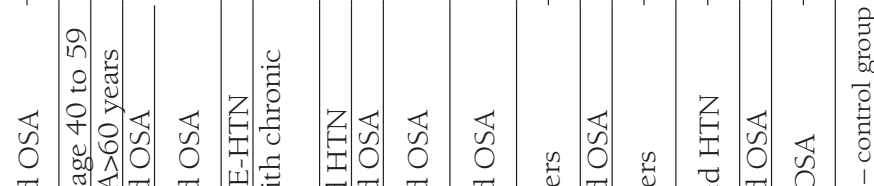<smiles>C1C[Si]2CCC12</smiles>

西

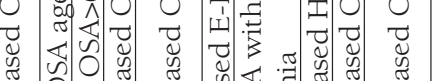

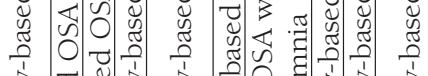
音

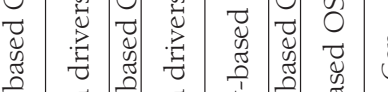

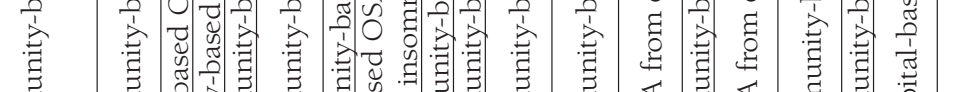
ป نे $ن$

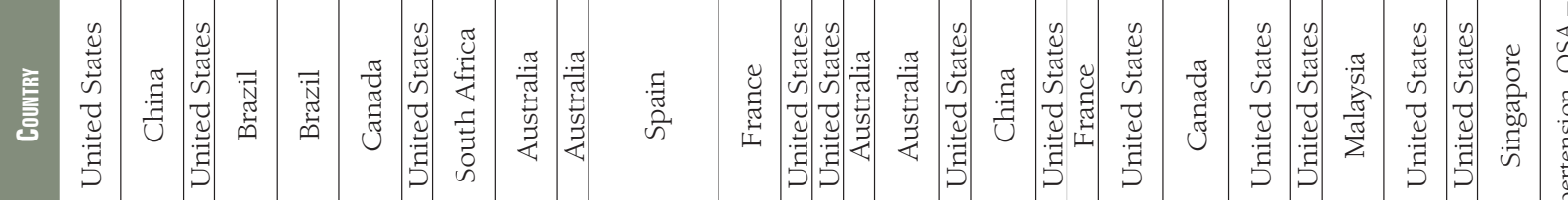

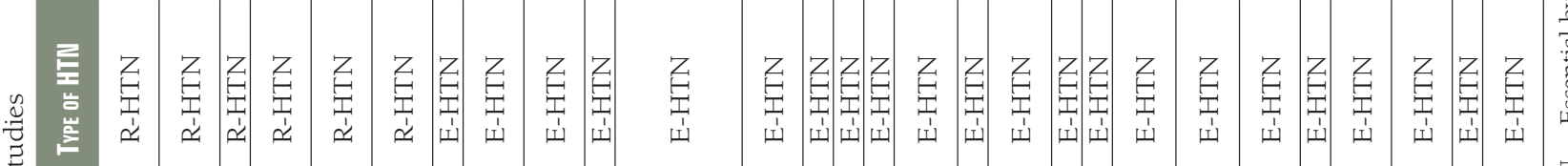

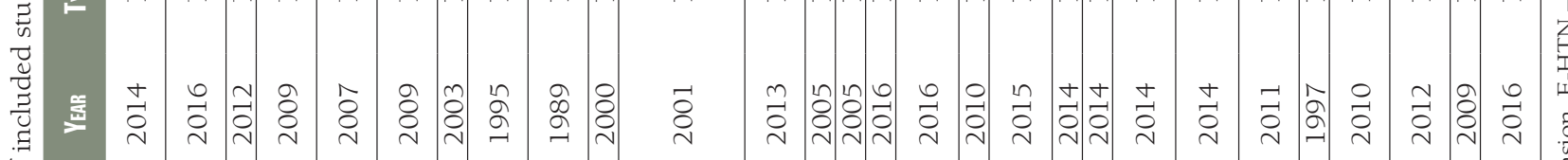

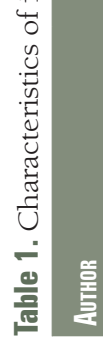

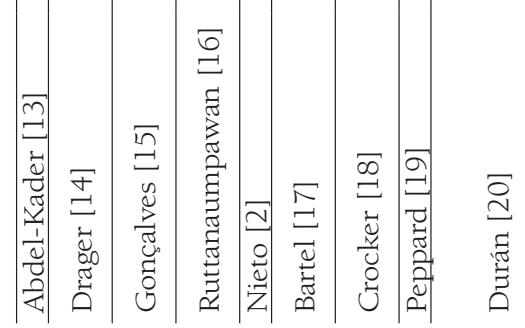

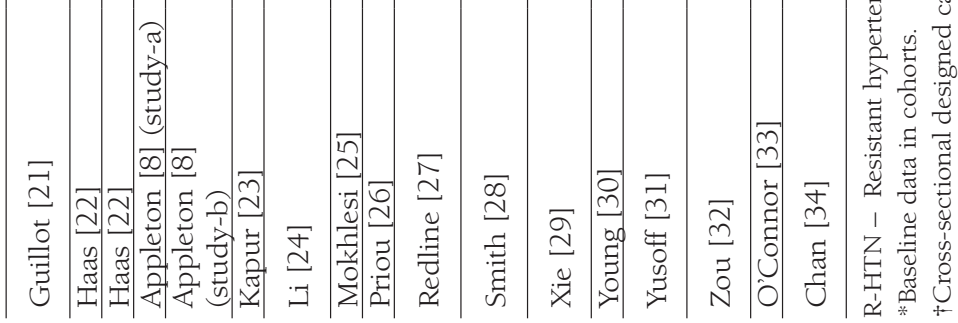


Table 2. Meta-analysis of association between OSA and hypertension

\begin{tabular}{|c|c|c|c|c|c|c|c|c|}
\hline \multirow{2}{*}{ TYPE OF HTN } & \multirow{2}{*}{ Category of OSA } & \multirow{2}{*}{ Subgroup } & \multicolumn{3}{|c|}{ EFFECt SIzE } & \multicolumn{3}{|c|}{ Heterogeneity test } \\
\hline & & & Pooled OR & $95 \% \mathrm{CI}$ & $\mathbf{P}$ & $I^{2}(\%)$ & Q & $\mathbf{P}$ \\
\hline \multirow[t]{3}{*}{ Resistant HTN } & OSA/non-OSA & Asian & 2.460 & $1.500-4.040$ & $<0.05$ & - & - & - \\
\hline & OSA/non-OSA & Caucasian & 4.406 & $1.835-6.977$ & $<0.05$ & 0 & 0.47 & 0.977 \\
\hline & OSA/non-OSA & Overall & 2.842 & $1.703-3.980$ & $<0.05$ & 0 & 2.23 & 0.816 \\
\hline \multirow[t]{11}{*}{ Essential HTN } & Mild OSA & Prospective & 1.038 & $0.808-1.267$ & $>0.05$ & 64.8 & 5.69 & 0.058 \\
\hline & Mild OSA & Non-prospective & 1.210 & $1.112-1.309$ & $<0.05$ & 0 & 3.60 & 0.825 \\
\hline & Mild OSA & Overall & 1.184 & $1.093-1.274$ & $<0.05$ & 10.1 & 11.13 & 0.348 \\
\hline & Moderate OSA & Caucasian & 1.315 & $1.197-1.433$ & $<0.05$ & 8.0 & 16.30 & 0.362 \\
\hline & Moderate OSA & Prospective & 1.224 & $0.917-1.530$ & $>0.05$ & 12.6 & 3.43 & 0.329 \\
\hline & Moderate OSA & Non-prospective & 1.332 & $1.204-1.456$ & $<0.05$ & 5.4 & 12.69 & 0.392 \\
\hline & Moderate OSA & Overall & 1.316 & $1.198-1.434$ & $<0.05$ & 3.2 & 16.53 & 0.416 \\
\hline & Severe OSA & Caucasian & 1.549 & $1.275-1.824$ & $<0.05$ & 0 & 7.49 & 0.586 \\
\hline & Severe OSA & Prospective & 1.505 & $0.998-2.013$ & $>0.05$ & 0 & 1.00 & 0.608 \\
\hline & Severe OSA & Non-prospective & 1.584 & $1.258-1.909$ & $<0.05$ & 10.2 & 7.80 & 0.351 \\
\hline & Severe OSA & Overall & 1.561 & $1.287-1.835$ & $<0.05$ & 0 & 8.86 & 0.546 \\
\hline \multirow[t]{5}{*}{ Essential HTN } & OSA/non-OSA* & Asian & 1.583 & $1.160-2.007$ & $<0.05$ & 0 & 0.32 & 0.850 \\
\hline & OSA/non-OSA* & Caucasian & 1.928 & $1.600-2.256$ & $<0.05$ & 47.0 & 7.55 & 0.110 \\
\hline & OSA/non-OSA* & Prospective & 1.475 & $1.035-1.914$ & $<0.05$ & 0 & 0.02 & 0.881 \\
\hline & OSA/non-OSA* & Non-prospective & 1.972 & $1.651-2.294$ & $<0.05$ & 19.8 & 6.23 & 0.284 \\
\hline & OSA/non-OSA* & Overall & 1.799 & $1.539-2.058$ & $<0.05$ & 26.0 & 9.46 & 0.221 \\
\hline
\end{tabular}

HTN - hypertension, OSA - obstructive sleep apnea, OR - odds ratio; CI - confidence interval

* Meta-analysis of six studies only divided subjects into OSA and non-OSA groups.

had an extra 1.842-fold risk for resistant hypertension prevalence compared to non-OSA participants. Subgroup analysis exposited that this association was more outstanding among Caucasian populations $(\mathrm{OR}=4.406,95 \% \mathrm{CI}=1.835-6.977)$.

The heterogeneity test showed no significant heterogeneity generated across all primary studies $\left(\mathrm{I}^{2}=0 \%\right.$, $\mathrm{Q}=2.23, P=0.816)$.

\section{Association between OSA and essential hypertension}

Twenty studies investigated the relationship between OSA and essential hypertension [2,8,17-34]. Among them, 16 studies classified OSA patients into three grades based on AHI their scores, which were mild OSA (AHI>5), moderate OSA (AHI>15) and severe OSA (AHI>30). Since natural differences exists between mild OSA, moderate OSA and severe OSA, results were interpreted separately. As shown in Table

Study

cross-sectional

Young (1997)

Durán (2001)

Nieto (2001)

Haas (2005)

Haas (2005)

Kapur (2010)

Mokhlesi (2014)

Appleton (2016)

Subtotal $(\mathrm{I}$-squared $=0.0 \%, p=0.825)$

prospective

Peppard (2000)

O'Connor (2009)

Appleton (2016)

Subtotal $(\mathrm{I}$-squared $=64.8 \%, p=0.058$ )

Figure 3. Forest plots of the association between essential hypertension and mild obstructive sleep apnea (OSA).
2 and Figures 3 to 5, essential hypertension was significantly associated with OSA, in terms of mild OSA $(\mathrm{OR}=1.184$, 95\% CI $=1.093-1.274, P<0.05)$, moderate OSA $(\mathrm{OR}=1.316,95 \% \mathrm{CI}=1.198$ $1.434, P<0.05)$, and severe OSA $(\mathrm{OR}=1.561,95 \% \mathrm{CI}=1.287-1.835$, $P<0.05)$. These results showed the trend of that the more serious OSA is, the higher hypertension risk occurs. Subgroup analyses were conducted based on study design (prospective/non-prospective) and ethnicity. As shown in Table 2, no significant results were found in studies with prospective study design, which outlined the pooled ORs (95\% CIs) of 1.038 (0.808-1.267) for mild OSA, 1.224 (0.917-1.530) for moderate OSA, and $1.505(0.998-2.013)$ for severe OSA. The 
Study

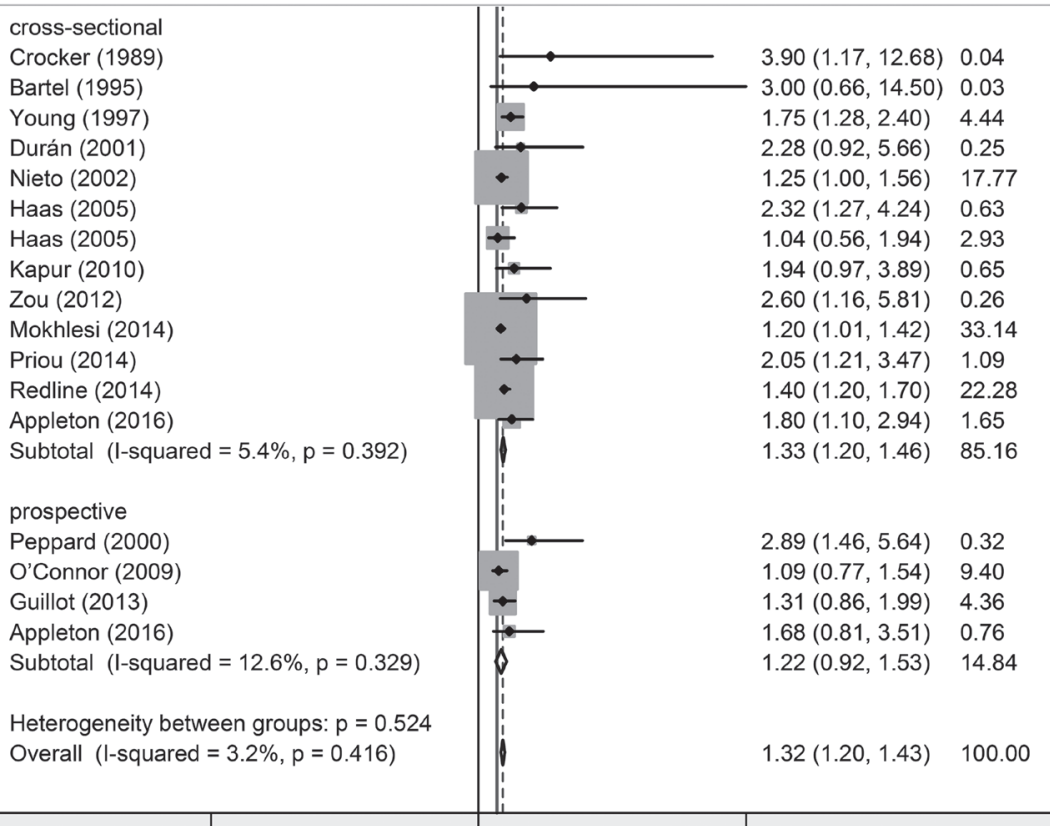

Figure 4. Forest plots of the association between essential hypertension and moderate obstructive sleep apnea (OSA).

\begin{tabular}{|c|c|c|c|}
\hline Study & & OR $(95 \% \mathrm{Cl})$ & Weight (\%) \\
\hline cross-sectional & & & \\
\hline Young (1997) & & $3.07(1.65,5.74)$ & 1.80 \\
\hline Nieto (2003) & $\leftarrow$ & $1.37(1.03,1.83)$ & 46.94 \\
\hline Haas (2005) & & $2.27(1.13,4.56)$ & 2.55 \\
\hline Haas (2005) & $\rightarrow$ & $1.30(0.63,2.71)$ & 6.94 \\
\hline Kapur (2010) & & $2.83(1.33,6.04)$ & 1.35 \\
\hline Priou (2014) & $\rightarrow$ & $2.33(1.33,4.10)$ & 3.92 \\
\hline Li (2015) & & $3.86(1.47,9.21)$ & 0.50 \\
\hline Appleton (2016) & - & $1.85(1.08,3.17)$ & 6.88 \\
\hline Subtotal $(I-$ squared $=10.2 \%, p=0.351)$ & $\diamond$ & $1.58(1.26,1.91)$ & 70.88 \\
\hline prospective & & & \\
\hline O'Connor (2009) & $\rightarrow$ & $1.50(0.91,2.46)$ & 12.50 \\
\hline Guillot (2013) & $\rightarrow$ & $1.77(1.11,2.80)$ & 10.52 \\
\hline Appleton (2016) & -1 & $1.06(0.43,2.65)$ & 6.10 \\
\hline Subtotal (I-squared $=0.0 \%, p=0.608$ ) & 1 & $1.51(1.00,2.01)$ & 29.12 \\
\hline Heterogeneity between groups: $p=0.799$ & & & \\
\hline Overall (I-squared $=0.0 \%, p=0.546$ ) & $\diamond$ & $1.56(1.29,1.83)$ & 100.00 \\
\hline $\begin{array}{c} \\
-9.21\end{array}$ & 1 & 21 & \\
\hline
\end{tabular}

Figure 5. Forest plots of the association between essential hypertension and severe obstructive sleep apnea OSA). heterogeneity test illustrated that $\mathrm{I}^{2}$ values were $10.1 \%(P=0.348)$ in mild OSA, $3.2 \%$ $(P=0.416)$ in moderate OSA, and $0 \%$ $(P=0.546)$ in severe OSA meta-analyses, indicating no significant heterogeneity in each group.

For the seven studies dividing participants only into OSA and non-OSA groups $[8,24,26,28,29,31,34]$, the pooled OR was $1.799(95 \% \mathrm{CI}=1.539-2.058$, $P<0.05$ ), demonstrating that OSA was associated with essential hypertension (Figure S1 and Table S2 in Online Supplementary Document). The subgroup analysis based on ethnicity showed significant results among Asians $(\mathrm{OR}=1.583$, $95 \% \mathrm{CI}=1.160-2.007)$ and Caucasians $(\mathrm{OR}=1.928,95 \% \mathrm{CI}=1.600-2.256)$. Additionally, no significant heterogeneity was found $\left(\mathrm{I}^{2}=26.0 \%, P=0.221\right)$. Four studies in the three articles reported the relationship between OSA and essential hypertension among male participants $[2,8,33]$. The combined result of these four studies suggested that the association between OSA and essential hypertension was relatively stronger among males $(\mathrm{OR}=1.698$, 95\% CI $=1.319-2.077$ ).

\section{Publication bias}

The funnel plot analysis, followed by Egger's test, was applied to detect the potential publication bias. Significant publication bias existed in the meta-analyses of moderate OSA and severe OSA participants, and the meta-analysis of resistant hypertension (Table 3 and Figures S7-S11 in Online Supplementary Document). The Trim and Fill analysis was performed to eliminate the effect of publication bias on meta-analysis. As shown in Table 3 and Figures S12-S14 in Online Supplementary Document, the pooled ORs (95\% CIs) were 1.327 (1.222-1.441) for moderate OSA and 1.593 (1.369-1.853) for severe OSA meta-analyses, and 1.575 (1.1172.221) for resistant hypertension.

Table 3. Analysis on publication bias and results of Trim and Fill method analysis

\begin{tabular}{|c|c|c|c|c|c|c|}
\hline \multirow{2}{*}{ TYPE of HTN } & \multirow{2}{*}{ Category of OSA } & \multicolumn{2}{|c|}{ Egger's TEST } & \multicolumn{3}{|c|}{ TRIM AND FILL METHOD ANALYSIS } \\
\hline & & $\mathbf{t}$ & $\mathbf{P}$ & Pooled OR & $95 \%$ CI & $\mathbf{P}$ \\
\hline Resistant HTN & OSA/non-OSA & 2.36 & 0.078 & 1.575 & $1.117-2.221$ & 0.010 \\
\hline Essential HTN & Mild OSA & 0.92 & 0.380 & 1.187 & $1.103-1.276$ & $<0.001$ \\
\hline Essential HTN & Moderate OSA & 3.91 & 0.001 & 1.327 & $1.222-1.441$ & $<0.001$ \\
\hline Essential HTN & Severe OSA & 1.98 & 0.079 & 1.593 & $1.369-1.853$ & $<0.001$ \\
\hline Essential HTN & OSA/non-OSA & 0.87 & 0.420 & 1.356 & $1.184-1.554$ & $<0.001$ \\
\hline
\end{tabular}

HTN - hypertension, OSA - obstructive sleep apnea, OR - odds ratio, CI - confidence interval 


\section{Sensitivity analysis}

To evaluate the robustness of the results, sensitivity analyses were undertaken by sequentially removing each study. Consequently, no obvious change was generated on omission of any individual study (Figure S2-S6 in Online Supplementary Document), confirming that the results of our meta-analyses were stable. This coincided with the results of heterogeneity tests.

\section{DISCUSSION}

This systematic review and meta-analysis was conducted in an effort to clarify the association between OSA and hypertension, including both essential and resistant hypertension. Our findings suggest that OSA confers a significant association with both essential and resistant hypertension. Moreover, OSA is associated with mild OSA, moderate OSA and severe OSA with a stepwise increased degree.

OSA are acknowledged to be associated with hypertension [6,7]. Nevertheless, the potential mechanisms underlying the associations have not been well elucidated. Several potential explanations may help us to understand the association of OSA and hypertension. OSA induces intermittent hypoxemia, similarly to hypoxia/reperfusion injury, and causes oxidative stress, leading to dysfunction of vascular endothelium [35]. Meanwhile, excessive outflow of sympathetic vasoconstrictor together with diminished nitric oxide bioavailability plays a role in blood pressure elevation [36,37]. In addition, episodes of OSA up-regulate sympathetic excitation which acts on the chemoreflex and may consequently result in hypertension $[10,38]$. In clinical observations, sympathetic nervous activity, reflected by 24-hour urinary catecholamine excretion, is increased in individuals with sleep-disordered breathing [39]. The data from relevant surveys revealed that the prevalence rate of OSA is $70-83 \%$ in resistant hypertensive patients [40]. It is also suggested that untreated OSA may lead to reduced effectiveness of medications through pharmacokinetic or chronotherapeutic effects, activating a pathway of resistance to antihypertensive drugs [1]. In the present study, we found that OSA strongly predisposes to resistant hypertension by combining six relevant studies. The pooled OR of the causal association in Caucasians is 4.406, which indicates Caucasians with OSA suffer more from uncontrolled hypertension.

OSA is also considered to be associated with essential hypertension and the consequences of cardiovascular diseases. However, the results are not entirely consistent, meanwhile more than eight studies have generated non-significant results $[2,8,13,17,20,22-23,33]$. This meta-analysis, involving 20 original studies in 19 articles, demonstrates that OSA increases the risk of essential hypertension in a dose-response manner. Although the dose-response meta-analysis has not been conducted owing to the lack of current available data, the trend of pooled ORs shows obviously that the more serious OSA is, the higher hypertension risk occurs.

Gender is indispensable factor in the analysis of demographic data. Nonetheless, seldom studies reported the association between OSA and hypertension in specific gender. O'Connor et al. reported that female patients with moderate and severe OSA have higher prevalence of essential hypertension than male [33], while, Nieto et al reported a lower OR in severe OSA women before [2]. After combining four studies reported in three articles $[8,29,31]$, our finding enlightens that men suffer from higher incidence of essential hypertension than women, as well the association in Caucasians is greater than that in Asians. These differences may be explained by the larger proportion of overweight and obesity among Caucasians and also among men [18]. This finding is consistent with a recent study by Cano-Pumarega et al., despite the fact that their study did not diagnose OSA with polysomnography and AHI [41]. Regarding ethnic subgroup analysis, the different results may subject to genetic backgrounds, environmental factors and genetic-environmental interaction $[42,43]$.

Heterogeneity may result from diversity of clinical study design or statistical methodology, and the detection of heterogeneity is essential for meta-analysis. No significant heterogeneity was found in the present study, indicating high compatibility of our results. Care must be taken in the adjustment of potential confounding factors in the statistical analysis of clinical studies. Obviously, obesity and age are both contributing factors to OSA and hypertension. Although investigators suggested that the impact of body mass index (BMI) on OSA is quite modest and adjustment for BMI might be an over-adjustment [2,32], we have synthesized the OR adjusted for both age and BMI in order to estimate the risk more precisely.

Publication bias, a critical issue in systematic review, mainly results from the tendency that studies with positive results are more likely to be published than those with negative findings. Significant publication 
bias exists in our meta-analyses of moderate OSA, severe OSA and essential hypertension. To reduce potential confounding of publication bias, we carried out the Trim and Fill analysis. According to the results of Trim and Fill analysis, the pooled ORs remained statistically significant for the association between moderate OSA and essential hypertension, the association between severe OSA and essential hypertension, as well as the association between OSA and resistant hypertension.

Comparing to low specificity of sleep questionnaires, AHI is an accurate parameter for determining OSA [14], which is defined as the number of episodes of apneas or hypopneas in 1 hour of sleep, recorded with polysomnography test [2]. One of inclusion criteria in this study is the usage of AHI as OSA diagnostic index, this obviously limits the number of studies to be included.

This study has certain limitations that are common in systematic reviews meta-analyses of descriptive studies: First, most of the original studies were based on cross-sectional designed investigation, which may limit the argumentation intensity of our conclusion. Second, the subgroup analyses based on age were not performed because of no primary data available from the included studies. Only 5 prospective studies $[8,19,21,33,34]$ meeting the inclusion criteria were included, and the pooled results of the studies showed no statistical significance of association between OSA and hypertension. However, the number of included studies/patients is small. More prospective studies need to be conducted to clarify the relationship between OSA and hypertension.

The present study demonstrates that OSA is related to an increased risk of resistant hypertension, with a stronger association among Caucasian populations and male OSA patients. Mild, moderate and severe OSA are associated essential hypertension, as well a dose-response manner is manifested.

Our interpretation of synthesized epidemiological evidence strengthens the acceptance of OSA as a risk factor of hypertension, in term of essential hypertension and resistant hypertension. Given the underlying mechanisms have been explained, the key remaining questions are how does OSA mediate hypertension and how can we implement specific interventions to reduce hypertension induced by OSA. More studies should be conducted to examine the mechanisms of hypertension regulation by OSA, especially among medication-resistant hypertension patients.

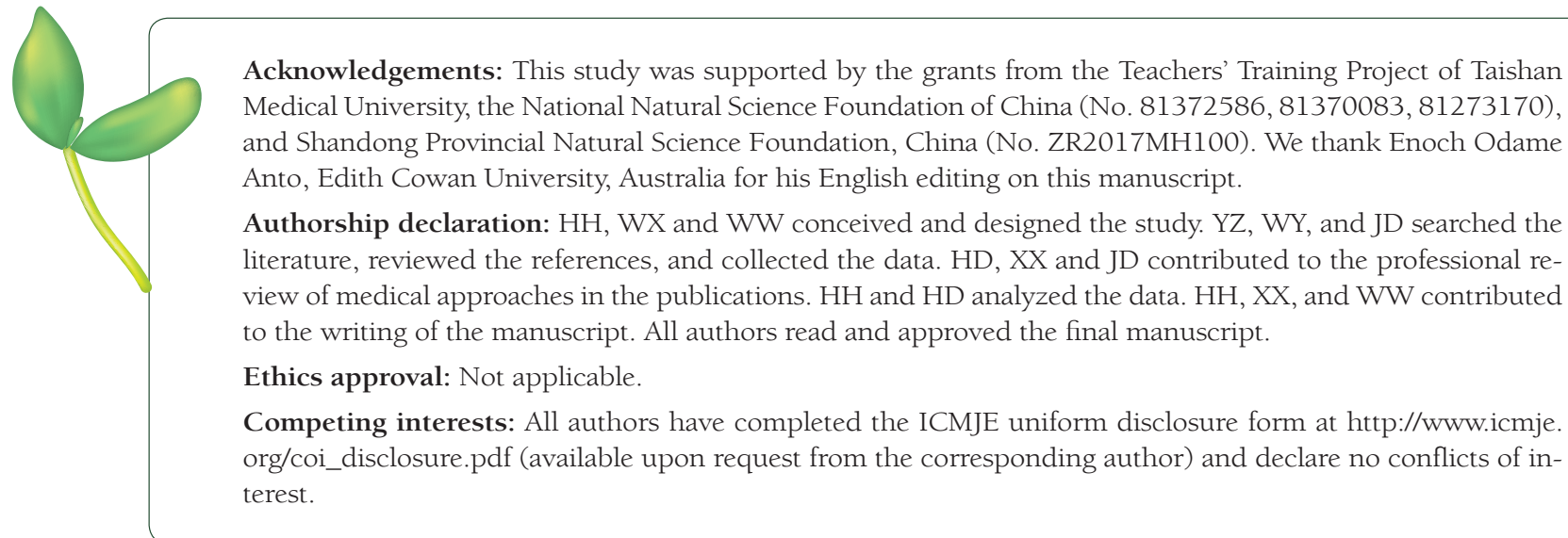

1 Walia HK, Li H, Rueschman M, Bhatt DL, Patel SR, Quan SF, et al. Association of severe obstructive sleep apnea and elevated blood pressure despite antihypertensive medication use. J Clin Sleep Med. 2014;10:835-43. Medline:25126027

2 Nieto FJ, Young TB, Lind BK, Shahar E, Samet JM, Redline S, et al. Association of sleep - disordered breathing, sleep apnea, and hypertension in a large community - based study. Sleep Heart Health Study. JAMA. 2000;283:1829-36. Medline:10770144 doi:10.1001/jama.283.14.1829

3 Marin JM, Agusti A, Villar I, Forner M, Nieto D, Carrizo SJ, et al. Association between treated and untreated obstructive sleep apnea and risk of hypertension. JAMA. 2012;307:2169-76. Medline:22618924 doi:10.1001/jama.2012.3418

4 Dempsey JA. 1, Veasey SC, Morgan BJ, O’Donnell CP. Pathophysiology of sleep apnea. Physiol Rev. 2010;90:47-112. Medline:20086074 doi:10.1152/physrev.00043.2008

5 Friedman O, Logan AG. The price of obstructive sleep apnea - hypopnea: hypertension and other ill effects. Am J Hypertens. 2009;22:474-83. Medline:19265785 doi:10.1038/ajh.2009.43

6 Muxfeldt ES, Margallo V, Costa LM, Guimarăes G, Cavalcante AH, Azevedo JC, et al. Effects of continuous positive airway pressure treatment on clinic and ambulatory blood pressures in patients with obstructive sleep apnea and resistant hypertension: a randomized controlled trial. Hypertension. 2015;65:736-42. Medline:25601933 doi:10.1161/HYPERTENSIONAHA. 114.04852 
7 Thunström E, Manhem K, Rosengren A, Peker Y. Blood pressure response to losartan and continuous positive airway pressure in hypertension and obstructive sleep apnea. Am J Respir Crit Care Med. 2016;193:310-20. Medline:26414380 doi:10.1164/rccm.201505-09980C

8 Appleton SL, Vakulin A, Martin SA, Lang CJ, Wittert GA, Taylor AW, et al. Hypertension is associated with undiagnosed obstructive sleep apnea during rapid eye movement (REM) sleep. Chest. 2016;150:495-05. Medline:27001264 doi:10.1016/j.chest.2016.03.010

9 Guo J, Sun Y, Xue LJ, Huang ZY, Wang YS, Zhang L, et al. Effect of CPAP therapy on cardiovascular events and mortality in patients with obstructive sleep apnea: a meta-analysis. Sleep Breath. 2016;20:965-74. Medline:26873722 doi:10.1007/s11325-016-1319-y

10 Fava C, Dorigoni S, Dalle Vedove F, Danese E, Montagnana M, Guidi GC, et al. Effect of CPAP on blood pressure in patients with OSA/hypopnea a systematic review and meta-analysis. Chest. 2014;145:762-71. Medline:24077181 doi:10.1378/chest.13-1115

11 James PA, Oparil S, Carter BL, Cushman WC, Dennison-Himmelfarb C, Handler J, et al. 2014 evidence-based guideline for the management of high blood pressure in adults: report from the panel members appointed to the Eighth Joint National Committee (JNC 8). JAMA. 2014;311:507-20. Medline:24352797 doi:10.1001/jama.2013.284427

12 Wu Y, Hu G, Pan F, Liu J, Mo X, Xie Y, et al. Obstructive sleep apnea hypopnea syndrome was a risk factor for uncontrolled hypertension in adult snorers in South China. Clin Exp Hypertens. 2016;38:429-34. Medline:27359186 doi:10 .3109/10641963.2016.1151525

13 Abdel-Kader K, Dohar S, Shah N, Jhamb M, Reis SE, Strollo P, et al. Resistant hypertension and obstructive sleep apnea in the setting of kidney disease. J Hypertens. 2012;30:960-6. Medline:22388231 doi:10.1097/HJH.0b013e328351d08a

14 Drager LF, Genta PR, Pedrosa RP, Nerbass FB, Gonzaga CC, Krieger EM, et al. Characteristics and predictors of obstructive sleep apnea in patients with systemic hypertension. Am J Cardiol. 2010;105:1135-9. Medline:20381666 doi:10.1016/j. amjcard.2009.12.017

15 Gonçalves SC, Martinez D, Gus M, de Abreu-Silva EO, Bertoluci C, Dutra I, et al. Obstructive sleep apnea and resistant hypertension: a case-control study. Chest. 2007;132:1858-62. Medline:18079220 doi:10.1378/chest.07-1170

16 Ruttanaumpawan P, Nopmaneejumruslers C, Logan AG, Lazarescu A, Qian I, Bradley TD. Association between refractory hypertension and obstructive sleep apnea. J Hypertens. 2009;27:1439-45. Medline:19421073 doi:10.1097/ HJH.Ob013e32832af679

17 Bartel PR, Loock M, van der Meyden C, Robinson E, Becker P. Hypertension and sleep apnea in black South Africans. A case control study. Am J Hypertens. 1995;8:1200-5. Medline:8998254 doi:10.1016/0895-7061(95)00387-8

18 Crocker BD, Olson LG, Saunders NA, Hensley MJ, McKeon JL, Allen KM, et al. Estimation of the probability of disturbed breathing during sleep before a sleep study. Am Rev Respir Dis. 1990;142:14-8. Medline:2368960 doi:10.1164/ajrc$\mathrm{cm} / 142.1 .14$

19 Peppard PE, Young T, Palta M, Dempsey J, Skatrud J. Longitudinal study of moderate weight change and sleep - disordered breathing. JAMA. 2000;284:3015-21. Medline:11122588 doi:10.1001/jama.284.23.3015

20 Durán J, Esnaola S, Rubio R, Iztueta A. Obstructive sleep apnea - hypopnea and related clinical features in a population - based sample of participants aged 30 to 70 yr. Am J Respir Crit Care Med. 2001;163:685-9. Medline:11254524 doi:10.1164/ajrccm.163.3.2005065

21 Guillot M, Sforza E, Achour-Crawford E, Maudoux D, Saint-Martin M, Barthélémy JC, et al. Association between severe obstructive sleep apnea and incident arterial hypertension in the older people population. Sleep Med. 2013;14:838-42. Medline:23831239 doi:10.1016/j.sleep.2013.05.002

22 Haas DC, Foster GL, Nieto FJ, Redline S, Resnick HE, Robbins JA, et al. Age - dependent associations between sleep disordered breathing and hypertension: importance of discriminating between systolic/diastolic hypertension and isolated systolic hypertension in the Sleep Heart Health Study. Circulation. 2005;111:614-21. Medline:15699282 doi:10.1161/01.CIR.0000154540.62381.CF

23 Kapur VK, Resnick HE, Gottlieb DJ; Sleep Heart Health Study Group. Sleep disordered breathing and hypertension: does self - reported sleepiness modify the association? Sleep. 2008;31:1127-32. Medline:18714785

24 Li Z, Li Y, Yang L, Li T, Lei F, Vgontzas AN, et al. Characterization of obstructive sleep apnea in patients with insomnia across gender and age. Sleep Breath. 2015;19:723-7. Medline:25601512 doi:10.1007/s11325-015-1121-2

25 Mokhlesi B, Finn LA, Hagen EW, Young T, Hla KM, Van Cauter E, et al. Obstructive sleep apnea during REM sleep and hypertension: results of the Wisconsin Sleep Cohort. Am J Respir Crit Care Med. 2014;190:1158-67. Medline:25295854 doi:10.1164/rccm.201406-11360C

26 Priou P, Le Vaillant M, Meslier N, Paris A, Pigeanne T, Nguyen XL, et al. Cumulative association of obstructive sleep apnea severity and short sleep duration with the risk for hypertension. PLoS One. 2014;9:e115666. Medline:25531468 doi:10.1371/journal.pone.0115666

27 Redline S, Sotres-Alvarez D, Loredo J, Hall M, Patel SR, Ramos A, et al. Sleep - disordered breathing in Hispanic/Latino individuals of diverse backgrounds. The Hispanic Community Health Study/Study of Latinos. Am J Respir Crit Care Med. 2014;189:335-44. Medline:24392863 doi:10.1164/rccm.201309-17350C

28 Smith R, Ronald J, Delaive K, Walld R, Manfreda J, Kryger MH. What are obstructive sleep apnea patients being treated for prior to this diagnosis? Chest. 2002;121:164-72. Medline:11796446 doi:10.1378/chest.121.1.164

29 Xie W, Chakrabarty S, Levine R, Johnson R, Talmage JB. Factors associated with obstructive sleep apnea among commercial motor vehicle drivers. J Occup Environ Med. 2011;53:169-73. Medline:21270659 doi:10.1097/JOM. Ob013e3182068ceb 
30 Young T, Peppard P, Palta M, Hla KM, Finn L, Morgan B, et al. Population - based study of sleep - disordered breathing as a risk factor for hypertension. Arch Intern Med. 1997;157:1746-52. Medline:9250236 doi:10.1001/ archinte.1997.00440360178019

31 Yusoff MF, Baki MM, Mohamed N, Mohamed AS, Yunus MR, Ami M, et al. Obstructive sleep apnea among express bus drivers in Malaysia: important indicators for screening. Traffic Inj Prev. 2010;11:594-9. Medline:21128189 doi:10.108 O/15389588.2010.505255

32 Zou D, Eder DN, Eskandari D, Grote L, Boström KB, Lindblad U, et al. Association between short total sleep time and hypertension: the Skara Sleep Cohort. J Hypertens. 2013;31:345-51. Medline:23196899 doi:10.1097/ HJH.Ob013e32835bf798

33 O'Connor GT, Caffo B, Newman AB, Quan SF, Rapoport DM, Redline S, et al. Prospective study of sleep - disordered breathing and hypertension: the Sleep Heart Health Study. Am J Respir Crit Care Med. 2009;179:1159-64. Medline:19264976 doi:10.1164/rccm.200712-18090C

34 Chan PF, Tai BC, Loo G, Koo CY, Ong TH, Yeo TC, et al. Optimal Body Mass Index cut - offs for identification of patients with coronary artery disease at high risk of obstructive sleep apnoea. Heart Lung Circ. 2016;25:847-54. Medline:27067667 doi:10.1016/j.hlc.2016.02.010

35 Lavie L. Obstructive sleep apnoea syndrome-an oxidative stress disorder. Sleep Med Rev. 2003;7:35-51. Medline:12586529 doi:10.1053/smrv.2002.0261

36 Pratt-Ubunama MN, Nishizaka MK, Boedefeld RL, Cofield SS, Harding SM, Calhoun DA. Plasma aldosterone is related to severity of obstructive sleep apnea in participants with resistant hypertension. Chest. 2007;131:453-9. Medline:17296647 doi:10.1378/chest.06-1442

37 Pimenta E, Stowasser M, Gordon RD, Harding SM, Batlouni M, Zhang B, et al. Increased dietary sodium is related to severity of obstructive sleep apnea in patients with resistant hypertension and hyperaldosteronism. Chest. 2013;143:97883. Medline:23288434 doi:10.1378/chest.12-0802

38 Dopp JM, Reichmuth KJ, Morgan BJ. Obstructive sleep apnea and hypertension: mechanisms, evaluation, and management. Curr Hypertens Rep. 2007;9:529-34. Medline:18367017 doi:10.1007/s11906-007-0095-2

39 Zhang J, Ma RC, Kong AP, So WY, Li AM, Lam SP, et al. Relationship of sleep quantity and quality with 24-hour urinary catecholamines and salivary awakening cortisol in healthy middle-aged adults. Sleep. 2011;34:225-33. Medline:21286244 doi:10.1093/sleep/34.2.225

40 Logan AG, Perlikowski SM, Mente A, Tisler A, Tkacova R, Niroumand M, et al. High prevalence of unrecognized sleep apnoea in drugresistant hypertension. J Hypertens. 2001;19:2271-7. Medline:11725173 doi:10.1097/00004872200112000-00022

41 Cano-Pumarega I, Barbé F, Esteban A, Martínez-Alonso M, Egea C. Durán - Cantolla J. Sleep Apnea and Hypertension: Are there sex differences? The Vitoria Sleep Cohort. Chest. 2017;152:742-50. Medline:28300571 doi:10.1016/j. chest.2017.03.008

42 Xi F, Wang Z, Qi Y, Brightwell R, Roberts P, Stewart A, et al. Long-term effect of respiratory training for chronic obstructive pulmonary disease patients at an outpatient clinic: a randomised controlled trial. Clin Transl Med. 2015;4:31. Medline:26458936 doi:10.1186/s40169-015-0073-2

43 Wang Y, Klarić L, Yu X, Thaqi K, Dong J, Novokmet M, et al. The association between glycosylation of immunoglobulin g and hypertension: A multiple ethnic cross-sectional study. Medicine (Baltimore). 2016;95:e3379. Medline:27124023 doi:10.1097/MD.0000000000003379 